\title{
BMJ Open Perspectives of UK Pakistani women on their behaviour change to prevent type 2 diabetes: qualitative study using the theory domain framework
}

To cite: Penn L, Dombrowski SU, Sniehotta FF, et al. Perspectives of UK Pakistani women on their behaviour change to prevent type 2 diabetes: qualitative study using the theory domain framework. BMJ Open 2014:4:e004530.

doi:10.1136/bmjopen-2013004530

- Prepublication history for this paper is available online. To view these files please visit the journal online (http://dx.doi.org/10.1136/ bmjopen-2013-004530).

Received 22 November 2013 Revised 16 June 2014 Accepted 17 June 2014

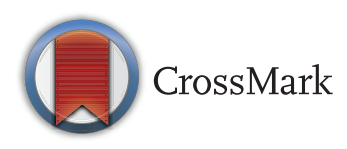

${ }^{1}$ Institute of Health and Society, Newcastle University, Newcastle upon Tyne, UK ${ }^{2}$ Fuse, UKCRC Centre for Translational Research in Public Health

${ }^{3}$ Division of Psychology, School of Natural Sciences, University of Stirling, Stirling, UK

Correspondence to Dr Linda Penn;

linda.penn@ncl.ac.uk

\section{ABSTRACT}

Background: Type 2 diabetes (T2D) is a debilitating disease, highly prevalent in UK South Asians, and preventable by lifestyle intervention. The 'New life, New you' (NLNY) physical activity (PA) and dietary intervention for T2D prevention was culturally adapted to better engage minority ethnic populations and tested for feasibility.

Objectives: To investigate Pakistani female participants' perspectives of their behaviour change and of salient intervention features.

Setting: A community-based 8-week programme of group delivered PA sessions with behavioural counselling and dietary advice, culturally adapted for ethnic minority populations, in an area of socioeconomic deprivation. Participants to NLNY were recruited through screening events in community venues across the town.

Participants: Interviews were conducted with 20 Pakistani female NLNY participants, aged 26-45 (mean 33.5) years, from different parts of town.

Results: Within the a priori Theoretical Domains Framework (intentions and goals, reinforcement, knowledge, nature of the activity, social role and identity, social influences, capabilities and skills, regulation and decision, emotion and environment), we identified the importance of social factors relating to participants' own PA and dietary behaviour change. We also identified cross-cutting themes as collateral benefits of the intervention including participants' 'psychological health'; 'responsibility' (for others' health, especially family members included in the new PA and diet regimes) and 'inclusion' (an ethos of accommodating differences).

Conclusions: Our findings suggest that culturally adapted interventions for Pakistani women at risk of T2D, delivered via group PA sessions with counselling and dietary advice, may encourage their PA and dietary behaviour change, and have collateral health and social benefits. The NLNY intervention appeared to be acceptable. We plan to evaluate recruitment, retention and likely effect of the intervention on participant behaviour prior to definitive evaluation.

\section{Strengths and limitations of this study}

This qualitative study:

- Highlighted cultural adaptations needed to engage Pakistani women in a lifestyle intervention.

- Identified unanticipated intervention benefits.

- Was limited by data collection early in the intervention timescale and the small study size.

\section{BACKGROUND}

Type 2 diabetes (T2D) is a debilitating disease that carries an increased risk of eye, kidney, nerve and vascular disease with decreased life expectancy. ${ }^{1}$ Prevalence of T2D is greater in UK residents of ethnic minority heritage than in the general UK population and the disease often occurs at an earlier age in these population groups. ${ }^{23}$ Although there is good research evidence for the efficacy of lifestyle interventions for prevention of $\mathrm{T} 2 \mathrm{D},{ }^{4}{ }^{5}$ translation of such evidence to service provision remains challenging. ${ }^{6} 7$ The UK National Institute for Health and Care Excellence (NICE) guidance for risk identification and preventive interventions for high-risk individuals was published in July 2012. ${ }^{1}$ This NICE guidance addresses the need to provide services, including risk assessment for those aged 2539 years who are not included in the National Health Service (NHS) Health Checks programme. The need to provide risk assessment and preventive opportunities for adults younger than those included in the NHS Health Checks is particularly relevant for ethnic minorities. ${ }^{1}$

The 'New life, New you' (NLNY) intervention for primary prevention of T2D was developed in Middlesbrough and has to date been evaluated through a feasibility study. ${ }^{8-10}$ According to UK government statistics, Middlesbrough ranks as 1 of the 10 most 
deprived areas in England based on the Index of Multiple Deprivation (IMD) ranks of localities within the town. ${ }^{11}$ The original NLNY intervention primarily targeted middle and older aged adults in low-income groups, priority groups identified using market segmentation of the Sport England Active People survey. ${ }^{12}$ The NLNY intervention was designed to be delivered in leisure and community settings and to recruit participants directly from the community, rather than relying on a health services referral route. Recruits to the NLNY intervention were assessed for individual risk of future T2D, using the Finnish Diabetes Risk Score (FINDRISC). ${ }^{13}$ The NLNY intervention promoted increased physical activity (PA), healthy eating and weight loss, in line with the UK NICE guidance. ${ }^{1}$ The intervention was delivered through an 8-week programme of weekly supervised PA sessions, each followed by reflection, behavioural counselling and advice, with ongoing support and follow-up assessment at 6 and 12 months. ${ }^{14}$ Details of the original NLNY intervention feasibility study has been published. ${ }^{810}$ We have described the design of the 8-week programme in terms of experiential learning, which emphasises the central role of a 'here and now' experience (in this case, experience of a PA) along with observation and reflection in promoting actions. ${ }^{14}$

In Middlesbrough, minority ethnic communities comprise about $9 \%$ of the total population. The South Asian community is well established in the town and in 2011 comprised about $6.1 \%$ of the total population (8461 of a total population of 138 700). ${ }^{15}$ Most of the South Asians in Middlesbrough are of Pakistani heritage, although there are also people of Indian and Bangladeshi heritage. Other ethnic groups in Middlesbrough include Black African and Chinese communities. Although participants from ethnic minorities were not excluded from the original NLNY intervention, few were recruited. To better engage members of the local ethnic minority communities, we planned a cultural adaptation of the NLNY intervention. We also extended the age range of people that were eligible for the programme to include adults over 25 years with no upper age limit. ${ }^{16} 17$ The feasibility study for the adapted NLNY intervention, for men and women, is ongoing. We are collecting recruitment data, including ethnicity and outcome data comprising weight and waist measurements along with self-report data on PA, diet and quality of life at 6 and 12 months of follow-up in a before and after study.

Recruitment of South Asian participants to preventive interventions has proved difficult. ${ }^{18}$ We anticipated that the cultural needs of Muslim women might deter their engagement in PA unless these needs were recognised and addressed. In this paper, we report a qualitative interview study that was conducted as part of the feasibility and acceptability evaluation of the adapted NLNY intervention, in line with the Medical Research Council (MRC) guidance for the development and evaluation of complex interventions to improve health. ${ }^{19}$ Women from the Pakistani community were early recruits to the adapted NLNY programme, and this interview study was conducted at an early stage of the programme. We aimed to investigate Pakistani women's perspectives of their behaviour change and salient features of the culturally adapted NLNY programme. We planned this investigation, along with other outcomes of the feasibility study, to subsequently inform the optimisation of the intervention via discussion with the commissioners. This feasibility assessment will also inform future options for a definitive evaluation of the adapted NLNY programme.

\section{METHODS}

To develop the adapted intervention and its evaluation, the NHS commissioners convened an operational group that included community health champions as well as health and fitness workers. The adapted NLNY intervention was informed by mapping the distribution of ethnic minority communities within the local authority area, followed by stakeholder consultations. The project delivery was managed by an NHS health improvement specialist. One adaptation of the NLNY intervention specifically targeted Pakistani women. As anticipated, and confirmed in stakeholder consultations, the main concern for local Pakistani women was the availability of culturally appropriate services. ${ }^{20}$ Thus, the need for single sex PA group sessions was of paramount importance in adapting the NLNY intervention for this population. It was also evident that assessment events would need to be restricted to women only and would need to be conducted in community venues that were convenient and where possible familiar to the women. In addition, the commissioners anticipated that the women might be more likely to respond to trainers who had an appreciation of their Islamic cultural heritage and were able to commission a suitable provider and afford some funding for intervention-specific provider training.

\section{Intervention}

The intervention that was provided for the Pakistani women was delivered through a Community Interest Company (CIC). The CIC was founded and registered by three local women (two of Pakistani and one of Arabic heritage) who are directors of the company (NUR FITNESS CIC registration number 08143445 http://www.bis.gov.uk/cicregulator). The intervention was delivered by one CIC founder member, who recruited other local Pakistani women to assist with intervention delivery. These women received training to qualify as fitness trainers or, in some cases, training to deliver the nutritional aspects of the intervention. The researcher and the project manager also provided training for the delivery staff that was specific to the NLNY intervention, including data collection procedures, use of behavioural change techniques and information regarding the relevant NICE guidance. ${ }^{1}$ The NHS commissioners provided funding and facilitated these training opportunities. 
Participants were recruited to the adapted NLNY intervention for Pakistani women through women-only assessment events that were organised by the project manager in consultation with the intervention delivery staff and community health champions (members of the community who have received training to promote health messages locally). These events took place in community venues in the areas of the town partly populated by the Pakistani community. Initial individual risk assessment was based on FINDRISCs. ${ }^{13}{ }^{21}$ Other data were collected at the assessment events, including self-report PA and dietary data. Follow-up assessments, as part of the service delivery and feasibility evaluation, were planned at 6 and 12 months.

Women recruited to the intervention took part in an 8-week programme of weekly sessions, delivered to groups of between 10 and 20 women. The sessions comprised approximately 60 min of supervised group PA followed by $30 \mathrm{~min}$ of reflection and advice centred on dietary information and action planning. Participant received a booklet, written in English, that included information, goal setting and action planning prompts with space for recording their progress. The information provided about a healthy diet was specifically tailored to the participant group, incorporating their preferred foods and cooking styles. The participants were also able to access additional PA sessions at different times of the week, delivered by the same provider (NUR FITNESS CIC). These additional sessions were made available to participants both alongside and following the 8-week course. These sessions were provided at no cost to the participants for up to 6 months and later at low cost. Most of the activity sessions were delivered in community halls, including school halls. In the early stages of the programme, the women had access to a community gym, where their exclusive use was assured for some mornings, but this facility was later closed.

The provider ensured that information about different sessions was easily available and regularly updated. This was facilitated via a social networking page (ie, Facebook) that the provider initiated; others relied on text messages, also from the provider, or accessed information by keeping in touch with other female participants.

\section{Design and participants}

All participants received information and gave written informed consent prior to taking part in the feasibility study and the interview study separately.

For the qualitative interview study, we purposively sampled participants to ensure representation from the three different areas of the town where early recruitment and intervention delivery took place. The interviews were scheduled early in the feasibility study, shortly after the first groups of women, all of whom were Pakistani, had completed their 8-week intervention programmes. The NLNY evaluation team did not have access to participant contact details, so the interview invitations and arrangements were made by the intervention delivery staff following guidance from the research team. The researcher who conducted the interviews did not know any of the participants prior to the interviews. Our previous work $^{9}$ and the Theoretical Domains Framework (TDF), ${ }^{22}$ a framework that groups component constructs from relevant behavioural theories into theoretical domains, were used to inform the topic guide for this study. The topic guide was refined as the interviews progressed.

\section{Data collection}

Group interviews involving two or at most three participants were planned to encourage participation and these were conducted in English language by the female researcher (LP). Resources for an interpreter were not available. The interviews were conducted in the community venues where the participants attended their PA sessions and were conducted in parallel with ongoing sessions, although always in a separate room. Interviews lasted between 60 and $75 \mathrm{~min}$. As in previous work, ${ }^{9}$ we allowed flexibility within the areas outlined in the topic guide and the women were encouraged to report what mattered to them. Active listening with prompts was employed to provide clarification and improve insight. Notes were made of related topics introduced by the participants and the topic guide was developed as the interviews progressed. All interviews were audiorecorded and transcribed, as close to verbatim as possible, by staff in the Institute of Health and Society at Newcastle University who have transcription expertise.

\section{Analysis}

We used the Framework approach ${ }^{23}$ for data analysis. Transcripts were read, checked and imported into NVivo $\mathrm{V} 9^{24}$ to facilitate coding. The themes emerging from the data were first classified according to the a priori theoretical domains identified from the TDF and included in the topic guide as: intentions and goals, reinforcement, knowledge, nature of the activity, social role and identity, social influences, capabilities and skills, behavioural regulation and decision, emotion and environment. LP performed the initial classification according to the TDF themes and these were then checked by SUD, differences being resolved through discussion. The use of NVivo software and the TDF defined a priori categories facilitated the analysis and promoted familiarisation with the data. Further analysis of the data within each of the theoretical domains, and reference to an empirical phenomenology approach, ${ }^{25}$ which is primarily about retaining the appreciation of the respondents' subjective world, led to the identification and agreement of crosscutting constructs.

\section{RESULTS}

We conducted nine interviews (seven dyad interviews and two interviews with groups of three participants). 
All 20 interview participants were recruited from among the first 78 female Pakistani intervention recruits in three areas of the town (Breckon Hill, Abingdon and Green Lane), with ages ranging from 26 to 45 years and a mean of 33.5 years. For this group of interview participants, their baseline risk of future T2D based on FINDRISC ranged from 11 to 22 with a mean score of 15. A FINDRISC of 11-14 represents moderate risk, with one in six likely to develop T2D within 10 years and a FINDRISC of 15-20 represents high risk with two in six likely to develop T2D within 10 years. The participants' English IMD scores, based on their postcodes of residence, ranged from 11 to 78 with a mean IMD score of 43 (which ranks among the most deprived English quintile). IMD scores are an ecological, composite measure based on routinely available data in seven categories of deprivation assessed at the Lower Super Output Area: a small administrative area with a population of about 1500. Details of participant characteristics are shown in table 1.

Some women were less confident in their use of English language than others and the women tended to organise themselves so that the interview groups included at least one participant who was confident in her own ability to express herself in English. Sometimes the women would converse briefly between themselves in their first language to check their use of English. Those who were more confident tended to speak more, although this was sometimes to clarify what the other person had said for the benefit of the researcher, who only spoke English. Quotes are assigned to groups (table 1) and where group discussion is reported we have used numerals (i, ii) to identify different speakers.

Within the a priori TDF (intentions and goals, reinforcement, knowledge, nature of the activity, social role and identity, social influences, capabilities and skills, regulation and decision, emotion and environment), we identified and analysed the anticipated themes relating to participants' own PA and dietary

\begin{tabular}{lclll} 
Table 1 & \multicolumn{4}{c}{ Participant baseline variables: group means } \\
\hline $\begin{array}{l}\text { Group } \\
\text { identifier }\end{array}$ & $\begin{array}{c}\text { Number in } \\
\text { the group }\end{array}$ & $\begin{array}{l}\text { Age } \\
\text { (years) }\end{array}$ & FINDRISC & $\begin{array}{l}\text { IMD } \\
\text { score* }\end{array}$ \\
\hline A & 2 & 33 & 20 & 46 \\
B & 2 & 30 & 12.5 & 52 \\
C & 2 & 31 & 13 & 78 \\
D & 3 & 35 & 15 & 69 \\
E & 2 & 36 & 13 & 20.5 \\
F & 2 & 40 & 14.5 & 37 \\
G & 3 & 32 & 14 & 18 \\
H & 2 & 29 & 14.5 & 29.6 \\
I & 2 & 45 & 17 & 34.5 \\
All & 20 & 34 & 15 & 43 \\
participants & \multicolumn{5}{l}{} \\
*A higher score indicates a higher level of deprivation. \\
FINDRISC, Finnish Diabetes Risk Score; IMD, Index of Multiple \\
Deprivation.
\end{tabular}

behaviours. We also identified three further cross-cutting themes which we have grouped as 'collateral health and social benefits'. These three composite themes related to participants' perspectives of (1) their psychological health; (2) their family role and responsibility for the health of others and (3) an ethos of inclusion and accommodation of differences.

\section{Participants own PA and dietary behaviours Intentions and goals}

Health concerns were frequently stated as a reason for taking part in the intervention and associated with an appreciation of the opportunity afforded by the availability of this intervention programme. There was an understanding of the increased diabetes risk associated with Asian ethnicity as described by one woman

I just about got myself motivated that it's for health reasons...especially with the diabetes...we as Asians, we get diabetes. (Group I)

Occasionally less explicitly health associated reasons would be mentioned such as

Because we will gonna be like fit and we are gonna be smart and look nice. (Group C)

The intervention documentation was organised by the provider to promote action planning. Participants were encouraged to write an action plan for themselves for the next week (such as drink a glass of water instead of a fizzy drink at lunchtime). This planning was recalled as explained in this quotation

Every week we give a self-challenge, we are not going to do this, we are not going to eat this, we are going to eat something else. (Group C)

More generally, goal setting was closely related to being part of the group and the need to engage with group activities

We have to go to the classes: we try our best to go to classes. (Group A)

\section{Reinforcement}

Most of the reinforcement centred on feedback from other people, especially others in the group, for example

It was pointed out that I was getting more defined on my waist and that was like really brilliant. It was a great motivator. (Group F)

\section{Knowledge}

Tailoring of dietary advice was much appreciated. There was frequent reporting of quantities of oil and salt to include in making home cooked curries, often introduced with an air of disbelief regarding how much oil and salt they had previously added to cooked food. They 
appreciated advice to reduce these quantities gradually so that the change in taste was less obvious, but they explained that as they became used to the different tastes they even preferred them.

Perhaps, surprisingly, the risk effect of family history needed clarification, as explained here

I know my uncle in Pakistani, he's got diabetes and his leg is quite bad actually. I didn't know, I didn't realise I would be at risk, because he's an uncle, he's not my dad and then it was quite a bit of a shock when they said no actually he's part of your family. (Group E)

\section{Nature of the activity, capabilities and skills}

There was a range of experience within this group of women. Many were quite new to the PAs that were presented in the programme and were gradually attuned to them by the trainers, as explained by one woman

They proper explain it, they do exercise and they keep telling us as well both ways. (Group A)

Generally, the opportunity to participate in PA was valued and the women were pleased with what they had achieved. One woman described her effort and the beneficial effects she felt

Trust me when I do work-out I'll be drenched, you know, and there's lots of ladies that really put the effort in, but it's like built your confidence. (Group G)

\section{Social role and identity, and social influences}

These domains were particularly important for this group of Pakistani women and additionally contribute to the cross-cutting collateral benefits that we identified (detailed below). The women were mostly homemakers and mothers and often described themselves in relation to this role

You put yourself back and you give your children more. (Group F)

The social responsibility to provide hospitality was sometimes seen as detrimental to their progress in achieving a healthy lifestyle

I have to buy some unhealthy foods in, just because it's the norm, people expect something like that on the table and what happens is, if I bought it in I'll end up eating it myself. (Group F)

There was an expectation that the CIC providers would understand and accept the social and cultural issues that were pertinent to this participant group, because the delivery staff themselves were from the Muslim community as described by one woman

Because she's [trainer] Asian as well, she knows how to change basically, she knows the things that Asians... whereas English people have different diet to what Asians do, our diet is totally different, whereas she helped us a lot by telling us small changes that we could make in our daily intake of food and the like type of cooking that we could do.

The appreciation of the efforts that were being made by the CIC providers who were known to many of the female participants was evident. This was described by one interviewee

I think [they are] helping our Asian community ladies, especially the oldies to come out [of the house]...They give her [the trainer] blessing. (Group D)

Recruitment by word of mouth was emphasised; people described how they had been encouraged to come by reassurance from those already engaged in the programme such as

Friends are like encouraging you. 'no you have to come, you have to come,' just it helps socialising and get out as well, because you don't realise you can get out (Group G), and it really helps to have someone saying actually it's ok to come. (Group B)

The women also described how later on they themselves had encouraged others and become 'champions' in promoting the intervention,

And then after I tell them it's really nice, come you see, it's really, really nice. (Group B)

\section{Regulation and decision}

Regulation centred on attending the PA sessions, where prompts to attend were naturally provided as part of the women's usual routine. For example, after taking the children to school, the women could attend a session in an adjacent community venue.

Every Monday we go, [to the activity session] like half nine till half ten. (Group C)

With regard to diet, there was some appreciation of the need for portion size control, for example, by using a smaller plate. Sweet fizzy drinks were perceived as addictive, therefore difficult to regulate and better avoided. The dietary advice offered included information about reading food labels, which was reported as helpful for making decisions about food choices. The fact that some sweet foods, specifically intended for Asian festivals, did not have nutrition labels was mentioned by some of the female participants.

\section{Emotion}

Worry about the risk of diabetes, because of family members with the disease, and concern for relatives already suffering from diabetic complications was often mentioned, sometimes with regret for those who had not been able to make beneficial lifestyle changes. Retinopathy was specifically mentioned where it had 
affected younger aged relatives to the detriment of their quality of life.

There was also some mention of possible embarrassment about going to the gym, described as

Making a fool of myself. (Group E)

In contrast, the enjoyment experienced by participating in the activity sessions was often mentioned.

We have a good laugh and we have good things. (Group C) But then the time flies by, you don't realised where the time has gone and you had a workout, but you had a laugh. (Group E)

It's the motivation of seeing each other and as well as having a laugh, you enjoy your time here. (Group B)

\section{Environment}

The main environmental issue, as anticipated for this population group, was the provision of a women-only facility. This is a broader criterion than just a single room, for example, in a leisure centre, set aside for an hour. This requirement includes access to changing and toilet facilities with reassurance that the area would be securely restricted to women during the sessions and no man would accidentally just walk in. There were also environmental issues of concern around the cold weather and the cost of attending sessions (once the free and subsidised period had expired).

It's so cold. At the moment I've stopped walking because it's cold. (Group A)

In the park all friends go together but sometimes I said I don't want to go 'it's too cold'. (Group D)

You have to look at it from the financial point of view, how much is the charge going to be? If I want to come three times a week how much is that going to be? (Group F)

Everything is expensive nowadays, just your basic household things cost an arm and a leg, so money is a big issue, but I think just for fitness the prices that they've got now are reasonable. (Group $\mathrm{H}$ )

\section{Collateral health and social benefits Psychological health}

Participants' perspectives of their psychological health involve subthemes relating to 'safety and freedom' (cultural acceptance and feeling comfortable) and 'positive affect' (feeling happier, less isolated and not depressed).

Reference to Islamic culture used in recruitment strategies was influential, as described by one participant

The advert [Radio Ramadan] was talking Islamic, like people in Islam history, the women. In those days women were like quite fit and strong and they had to be and that's what got me in [to the programme]. (Group D)

Similar references were used by the community provider during the sessions and contributed to the engagement strategies. This was reflected in perspectives of cultural acceptance that made the women comfortable

You know the instructor... and sometimes they talk in our own language and we just do jokes. (Group A)

Feeling safe and comfortable was a regular and much emphasised theme, as described clearly by members of one group

(i) It's easy for me to say, 'I'm going to a ladies only gym, there's no men there', and I know there will be no disapproval from the male side of our family.

(ii) I felt like the whole mental pressure was lifted because I could justify to anyone that I am in an entirely female environment.

(i) He [husband] is in the mind that my wife is in a safe environment. (ii) It is completely peaceful in mind. $($ Group F)

The relief from anxiety was expressed by one participant as

You can just do exercise, you are not like wary - is anyone [male] suddenly going to walk through the door. (Group D)

Other aspects of feeling safe were about confidence to exercise. For example

That's what they teach you, 'listen to your own body', whatever your body allows you go to that speed and level. With me being a blood pressure patient...Absolutely I found no fear, no worry and I was in a good safe environment. (Group F)

The purposeful social grouping, and the opportunity this presented for women to talk together and support each other appeared to promote greater confidence within participants' perceived role: as described by one woman when talking about cooking for the family

if you are the main cook then it's part of your role, if you got the knowledge [re: healthy food choices]. (Group G)

Another woman talked about cooking for her husband

When I go home I say, 'I'm going to cook and you are going to eat, this is how I am going to cook.' Husband was a bit like, you know, like it is -isn't it? 'Ah, you are not going to cook like that?' 'Oh yes I am, but it will taste nice.' (Group F)

There were also explicit references to depression and isolation such as

She [relative] spent time at home a lot and I think a lot of depression got to her. (Group E)

Contrast was made between this relative's experience and the beneficial effect the participants perceived 
through the option of taking part in appropriate social meeting.

Two women in another group discussed depression in explicit relation to the intervention and the difference participation in a social and active group made to them in comparison to their previous behaviours.

(i) If you stay home all day obviously it's different isn't it? I was very, very lazy. I didn't used to go out. I just used to stay at home all the time.

(ii) Watch TV.

(i) Watch TV and just do the housework and just eat. Sit down in one place. So now I am very active. This year we got the choice to get depressed or to go out and get fresh. (Group A)

Another woman talked about how she had lived in the area for 6 years, but previous to joining the programme had only known one friend. She explained how she had now been welcomed by the group and how she communicated with other women outside the sessions, such as about transport arrangements to get to classes where needed.

\section{Family role and responsibility for the health of others}

The women's pivotal role within the family as the main cook was perceived as conveying a responsibility for their family's health that was often explained such as

We have responsibility, we doing the shopping, we bring all the best things back for them. (Group D)

In relation to this, there were clear statements that the knowledge and support the women had received through the programme would empower them to make healthy changes for their own benefit with the added consequence of influencing other family and community members. One person clearly spoke about this as

By educating the women I think what you are doing is you are empowering the women to sort of make decisions, informed decisions cos they know that, 'this is right', 'this is wrong'. Then they are in turn helping their younger, and extended elders. (Group F)

Similarly another woman described how her perception of responsibility had changed

Now I go outside [of the house, to the sessions] I know what to do to my child you see. I want to give good things you know. (Group D)

A description of specific changes was supplied by another group

We have stopped biscuits, we stopped cakes, we stopped crisps, we stopped everything, even we stopped white bread as well, we start brown bread and everything like brown rice.

This confidence to change extended to encouraging their children to exercise and even jokingly to the possibility that they might influence their husbands as explained in discussion with laughter by one group

(i) I wanna send mine [husband].

(ii) Yeah, I said to mine, 'Get out there'.

(i) They are jealous wasn't it, looking at us, and now,

'Look we [imagining husbands' speaking] need to work out'. (Group G)

There was also an appreciation by the women of the way their own health would impact on others as explained in the following

I'm the one that makes-does everything, if for some reason my health suffers then everyone else in our family suffers. (Group E)

\section{An ethos of inclusion and accommodation of differences}

The Pakistani women within this group had a range of faith-related preferences. A particular example was that some women did not want to participate in activities that involved music and the other women in the activity group were encouraged, by the trainer, to respect and accommodate these wishes so the issue was resolved. This issue and its resolution were reported by one or two groups

Then [the trainer] said, 'No, they don't like music on' then [everyone] agree as well. They said, 'Oh you are so kind, because we don't like music.' (Group C)

Although this intervention targeted ethnic minority participants, the additional PA sessions run by the community provider were open to other paying customers and attracted a few of the local women from the white population, who were welcomed as described by one woman

Four white women were there and we had such a laugh with them as well, you know trying to speak our lingo and we were like, we tried like, the one that do speak English they are trying to say their words...we are having a laugh and everything. (Group E)

This inclusivity was similarly described by another group

(i) The more the merrier and I think as long as it is women only it doesn't matter what ethnicity or what race or what age, we don't care.

(ii) I'm sure women from non-Muslim background they will probably feel intimidated by gyms anyway and they might find coming to a women only gym- 'Wow this is great!' (Group F)

The women themselves even encouraged wider participation

I've been recommending it to lots of Asians [and] English ladies, because they [all] like Bollywood music don't they? (Group G) 
The appreciation of issues that would be common to all women was described by one group member as

When women work together from different cultures we all find that we have the same fears, the same sort of issues about our bodies and how we want to look better. (Group F)

\section{DISCUSSION}

\section{Main findings}

The NLNY intervention is unusual in being centred on group delivered PA sessions. The Pakistani women's appreciation of the opportunity to engage in group delivered PA sessions in a culturally appropriate and socially supportive environment was an important finding. This qualitative study suggests that provision of culturally appropriate PA sessions will facilitate the engagement of Pakistani women and encourage their PA and dietary behaviour change. The study results emphasise the importance of social influences and the women's own perceived social role and identity for intervention development. The fact that the delivery staff members were from the local Pakistani women's own community contributed to recruitment and engagement of the participants.

The engagement of Pakistani women in this culturally acceptable, social and proactively healthful context may have important health and social benefits in addition to those specifically intended by the intervention. We have described these unanticipated additional effects as 'collateral health and social benefits' and they comprise: a potential positive impact on the women's own psychological health including reduction in feelings of isolation and depression; improved knowledge and confidence with which to fulfil their perceived role as having responsibility for providing healthy food for their families and thus encouraging healthy lifestyles in their children; and an ethos of accommodation for the range of different cultural variation within local groups of women.

\section{Strengths and limitations}

This qualitative study was conducted quite early in the life of the intervention programme, when the women had been involved in the intervention for less than 6 months. It was not clear whether early enthusiasm for the intervention would be sustained. The interviews were conducted in English, which was not the participants' first language. Although participants could all speak some English and were able to translate for each other to an extent, the accuracy of these translations remains unclear. The small group, mostly dyadic, format for conducting the interviews, and the fact that they took place alongside intervention sessions that the women would usually be attending, facilitated study engagement. The disadvantage of this was that the interview rooms were not very quiet and so some of the recordings were difficult for the staff undertaking the transcriptions to construe. We were able to call on an experienced staff team to ensure the transcriptions were as accurate as possible. The interview arrangements were made by the intervention delivery staff, which could mean some bias in the choice of respondents, although we accessed women from different areas of the town and we were aware of a diverse range of cultural differences among the Pakistani women who participated. The researcher who conducted the interviews was not Pakistani and only spoke English; however, the interviewees were open and friendly, keen to communicate their views and to do so in a way that could be understood beyond their cultural group. The women who took part in the interview study were aged from 27 to 45 years and most were under 40 years of age. This is the younger age range of the typical target population for T2D prevention. We do not know how effective the intervention will be in attracting older women. There was some suggestion that these younger women might recruit older relations to take part in the intervention and it will be valuable to assess the recruitment age profile over time.

\section{Comparison with other studies and implications}

The NICE guidance for risk identification and provision of preventive interventions for high-risk individuals included recommendations for adults aged 25-39 of South Asian ethnicity, who are not included in the NHS Health Checks programme. ${ }^{1}$ The findings from a recent National Institute for Health Research (NIHR) Health Technology Assessment evidence synthesis confirmed the importance of adapting health promotion interventions for ethnic minority communities and suggested that adaptation decisions should be based on detailed understanding of the target community. ${ }^{16}$ Our plans for the adaptation of the NLNY intervention ${ }^{10} 26$ to engage people from the local ethnic minority communities were therefore appropriate. The service commissioners took the lead in convening an operational group that included representation from the evaluation team. The commissioners were able to expand existing community links. Members of the local ethnic minority communities were invited to a dissemination seminar that was arranged to promote the NLNY intervention in its original format and invite interest in the adaptation.

In the interview study reported here, we sought to explore Pakistani female participants' views and, particularly in preparing the topic guide, we were able to draw on information from our qualitative evaluation within the original NLNY intervention. ${ }^{9}$ In the original NLNY intervention, community-based recruitment was successful, with 218 participants recruited to the programme from 367 registers of interest in under 2 years. The benefit of community-based recruitment procedures was also experienced in the PODOSA trial. ${ }^{27}$ Early indications from this interview study suggest the potential of community-based recruitment strategies for Pakistani women. The adapted NLNY intervention was unusual in 
being provided through a CIC. ${ }^{28}$ It was evident that some of the women interviewed knew the intervention providers and that this positively affected their confidence and decision to participate.

The social support engendered by the nature of the intervention was evident, as it was in the original NLNY intervention, and this reflects the more general literature around social support and behaviour change. ${ }^{29}$ The social needs of this specific participant group to undertake various physical activities were of paramount importance for their engagement and confidence to become involved in the intervention. Whereas other interventions may be counselling based, whether this is individually or group delivered, NLNY centres on group delivered PA, which is provided as a fundamental pre-requisite of experiential learning. The provision of occasional women-only sessions in local authority leisure centres does not constitute ideal provision of appropriate facilities (eg, if the toilets are in common areas). In this feasibility phase, the provision of staff training so that women from the Pakistani community could conduct PA sessions in appropriate and convenient community venues, including school premises, was of immediate importance for the continued intervention delivery.

The identification of beneficial effects on other aspects of participants' own health that may result from their participation in PA intervention delivered in social groups and the 'spill over' effects of health promotion on other family members is supported by other evidence ${ }^{30-33}$ This additional benefit may have importance for health economic evaluation of interventions designed to promote increased PA, especially where these are delivered to groups that are organised to promote social support networks.

\section{Unanswered questions and future research}

The feasibility study of the adapted version of the NLNY intervention, which was planned to better engage members of the local ethnic minority communities, is ongoing and we plan to analyse the recruitment, retention and outcomes at 12 months follow-up by sex and ethnic group. The entire feasibility study, together with our previous work relating to the original NLNY intervention $^{8}$ and the related qualitative studies, including the interview study reported here, ${ }^{9}$ will inform plans for optimisation of the intervention and options for definitive evaluation of the NLNY intervention for effectiveness and cost-effectiveness.

Acknowledgements The authors thank the participants in the adapted version of the New life, New you intervention, particularly those who gave their time for these interviews. They thank the project implementation team including NHS health promotion staff and intervention delivery staff, especially Claire Robinson and Shazia Noor.

Contributors MW was a member of the Steering Group responsible for securing funding and for the outline plan for the original NLNY intervention and evaluation. LP contributed to the development of the NLNY pilot intervention and designed the feasibility evaluation. Adaptation of the NLNY intervention was later planned to better engage local ethnic minority communities. This interview study was planned by LP as part of the evaluation of the adapted NLNY intervention. LP conducted the interviews. FFS, SUD and MW provided advice on the analysis. LP conducted the preliminary analysis which was then discussed and agreed with SUD. MW, FFS and SUD reviewed and contributed to the manuscript drafted by LP. All authors read and agreed on the final version.

Funding Integral to the London 2012 Olympic and Paralympic Games was the aspiration that the Games would encourage more people across the UK to participate in physical activity. In the North East of England this Olympics vision and the regional health strategy provided the foundation for the 'New life, New you' intervention that was originally funded as a 2012 Olympic Legacy Project by a consortium including: Sport England, Middlesbrough Council, Middlesbrough Primary Care Trust and the North East Strategic Health Authority. The adapted version of the New life, New you intervention was designed to better engage the local ethnic minority community and funded by Middlesbrough Primary Care Trust.

Competing interests MW and FFS are funded in part by the British Heart Foundation, Cancer Research UK, the Economic and Social Research Council, and Medical Research Council and National Institute of Health Research (NIHR) as director and senior investigator respectively of Fuse- the Centre for Translational Research in Public Health, which is a UKCRC Public Health Research Centre of Excellence. The business case and outline plan for the original 'New life, New you' study was determined by a steering committee. This included representatives from members of the organisations that comprised the funding consortium as well as the principal investigator for the evaluation, coauthor MW. The detailed development of the intervention was then progressed by a small operational team including the evaluation researcher, coauthor LP. The adapted version of the New life, New you intervention was funded by Middlesbrough PCT. MW, FFS, SUD and LP receive salaries from Newcastle University, Institute of Health and Society that provide open access funding for the publication.

Ethics approval Newcastle University Ethics Committee (Number 0447).

Provenance and peer review Not commissioned; externally peer reviewed.

Data sharing statement No additional data are available.

Open Access This is an Open Access article distributed in accordance with the Creative Commons Attribution Non Commercial (CC BY-NC 3.0) license, which permits others to distribute, remix, adapt, build upon this work noncommercially, and license their derivative works on different terms, provided the original work is properly cited and the use is non-commercial. See: http:// creativecommons.org/licenses/by-nc/3.0/

\section{REFERENCES}

1. NICE. PH 38 Preventing type 2 diabetes-risk identification and interventions for individuals at high risk. 2012. http://guidance.nice. org.uk/PH38 (accessed 17 Sept 2013).

2. Forouhi NG, Merrick D, Goyder E, et al. Diabetes prevalence in England, 2001-estimates from an epidemiological model. Diabet Med 2006;23:189-97.

3. Pollard TM. Ethnic groups as migrant groups: improving understanding of links between ethnicity/race and risk of type 2 diabetes and associated conditions*. Annu Rev Anthropol 2011;40:145-58.

4. Knowler WC, Barrett-Connor E, Fowler SE, et al. Reduction in the incidence of type 2 diabetes with lifestyle intervention or metformin N Engl J Med 2002;346:393-403.

5. Tuomilehto J, Lindstrom J, Eriksson JG, et al. Prevention of type 2 diabetes mellitus by changes in lifestyle among subjects with impaired glucose tolerance. N Engl J Med 2001;344:1343-50.

6. Costa B, Barrio F, Cabré JJ, et al. Delaying progression to type 2 diabetes among high-risk Spanish individuals is feasible in real-life primary healthcare settings using intensive lifestyle intervention. Diabetologia 2012:55:1319-28.

7. Jain SH, Horton ES, Kuc KK. Advancing the science and practice of diabetes prevention. Am J Prev Med 2013;44(4 Suppl 4):A1-4, S297-S400.

8. Penn L, Ryan V, White M. Feasibility, acceptability, and outcomes at 12 months follow-up of a novel community based intervention to prevent type 2 diabetes in adults at high risk: mixed methods pilot study. BMJ Open 2013;3:e003585. 
9. Penn L, Dombrowski SU, Sniehotta FF, et al. Participants' perspectives on making and maintaining behavioural changes in a lifestyle intervention for type 2 diabetes prevention: a qualitative study using the theory domain framework. BMJ Open 2013;3. pii: e002949.

10. Penn L, Lordon J, Lowry $\mathrm{R}$, et al. Towards the translation of research evidence to service provision: experience from North East England, UK. In: Schwarz P. ed. Diabetes prevention in practice. WCPD 2010 Dresden, 2010:189-97.

11. Neighbourhoods Statistical Release. The English Indices of Deprivation 2010. In: Department for Comunities and Local Government, ed. http://www.statistics.gov.uk: Crown Copywright, 2011.

12. Sport England. Active People Survey 1. Secondary Active People Survey 1 2007. http://www.sportengland.org/

13. Lindstrom J, Tuomilehto J. The diabetes risk score: a practical tool to predict type 2 diabetes risk. Diabetes Care 2003;26:725-31.

14. Kolb DA. Experiential learning: experience as the source of learning and development. EnglewoodCliffs, NJ: Prentice-Hall, 1984.

15. Office for National Statistics UK. Middlesbrough Local Authority. 2013. http://www.neighbourhood.statistics.gov.uk

16. Liu J, Davidson E, Bhopal R, et al. Adapting health promotion interventions to meet the needs of ethnic minority groups: mixed-methods evidence synthesis. Health Technol Assess 2012;16:1-469.

17. Netto G, Bhopal R, Lederle N, et al. How can health promotion interventions be adapted for minority ethnic communities? Five principles for guiding the development of behavioural interventions. Health Promot Int 2010;25:248-57.

18. Samsudeen BS, Douglas A, Bhopal RS. Challenges in recruiting South Asians into prevention trials: health professional and community recruiters' perceptions on the PODOSA trial. Public Health 2011;125:201-9.

19. MRC (Medical Research Council UK). Developing and evaluating complex interventions: new guidance. 2008. http://www.mrc.ac.uk/ Utilities/Documentrecord/index.htm?d=MRC004871. http://www.mrc. ac.uk/complexinterventionsguidance (accessed 17 Sept 2013).

20. Babakus W, Thompson J. Physical activity among South Asian women: a systematic, mixed-methods review. Int J Behav Nutr Phys Act 2012:9:150.
21. Davies M, Khunti K, Chauhan U, et al. The handbook for vascular risk assessment, risk reduction and risk management. University of Leicester, 2008.

22. Francis J, O'Connor D, Curran J. Theories of behaviour change synthesised into a set of theoretical groupings: introducing a thematic series on the theoretical domains framework. Implement Sci 2012;7:35.

23. Ritchie J, Lewis J, eds. Qualitative research practice: a guide for social science students and researchers. London: Sage Publications, 2003.

24. QSRInternational. NVivo 9. 2012

25. Aspers P. Empirical phenomenology: a qualitative research approach (The Cologne Seminars). Indo Pac J Phenomenol 2009;9:1-12.

26. Penn L, Lordon J, Lowry R, et al. Translating research evidence to service provision for prevention of type 2 diabetes: development and early outcomes of the 'New life, New you' intervention. Br J Diabetes Vasc Dis 2011;11:175-81.

27. Douglas A, Bhopal R, Bhopal R, et al. Recruiting South Asians to a lifestyle intervention trial: experiences and lessons from PODOSA (Prevention of Diabetes \& Obesity in South Asians). Trials 2011;:12:220.

28. Community Interest Companies. Department for business, education and skills, 2013 (accessed 17 Sept 2013).

29. Absetz P, Valve R, Oldenburg B, et al. Type 2 diabetes prevention in the 'real world': one-year results of the GOAL Implementation Trial. Diabetes Care 2007;30:2465-70.

30. Basu A, Meltzer D. Implications of spillover effects within the family for medical cost-effectiveness analysis. J Health Econ 2005;24:751-73.

31. Falba TA, Sindelar JL. Spousal concordance in health behavior change. Health Serv Res 2008;43(1 P1):96-116.

32. Goebbels AF, Lakerveld J, Ament AJ, et al. Exploring non-health outcomes of health promotion: the perspective of participants in a lifestyle behaviour change intervention. Health Policy 2012;106:177-86.

33. Gorin AA, Wing RR, Fava JL, et al. Weight loss treatment influences untreated spouses and the home environment: evidence of a ripple effect. Int J Obes 2008:32:1678-84. 